\title{
西双版纳不同林龄次生植物群落优势树种的热值
}

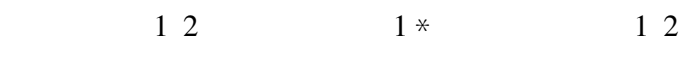 \\ （1 中国科学院西双版纳热带植物园昆明分部, 昆明 650223）（2 中国科学院研究生院, 北京 100049）
}

摘 要 该文对西双版纳的 4 种次生植物群落优势树种的热值进行了研究。4 种群落类型分别是山黄麻 (Trema orientalis) 群落、白背桐 (Mallotus paniculatus) 群落、中平树 (Macaranga denticulata) 群落和思茅崖豆 (Millettia leptobotrya) 群落 群落年龄分别为 $2 、 4 、 6$ 年和大于 15 年。 4 种群落各优势树种的平均干重热值分别为 $19182.11 、 19474.81$ 、 19551.38 和19 $445.95 \mathrm{~J} \mathrm{~g}^{-1}$ 。总体来讲, 热值随着群落年龄的增加而增加。增长的原因应该是群落光能利用效率 的增加。思茅崖豆群落的热值稍有降低, 是因为这个群落样地处在阴坡, 不能接受到像其它 3 个群落那样在阳坡 的充足光照。先锋树种的热值明显低于顶极树种。可能是因为在群落演替初期, 生态系统增加能量耗散的主要方 式是通过生物量的增加; 而当结构建成, 生物量增加到一定程度, 已经没有足够增长空间的时候, 生态系统将会改 变能量储存方式, 主要通过单位质量固定能量的增加, 也就是热值的增加 来耗散能量。山黄麻群落中叶片的热值 非常低, 低于根的热值水平, 是短命树种将能量更多地投资于繁殖的原因。

关键词 能量 热值 优势物种 次生演替 西双版纳

\section{CALORIC VALUES ALLOCATION OF DOMINANT SPECIES IN FOUR SECONDARY FORESTS AT DIFFERENT AGES IN XISHUANGBANNA , SOUTHWEST CHINA}

\author{
QIAO Xiu-Juan ${ }^{12}$, CAO Min ${ }^{1 *}$, and LIN Hua ${ }^{12}$ \\ ${ }^{I}$ Forest Ecosystem Research Center , Xishuangbanna Tropical Botanical Garden , Chinese Academy of Sciences , Kunming 650223 , China , and \\ ${ }^{2}$ Graduate University of Chinese Academy of Sciences , Beijing 100049 , China
}

\begin{abstract}
Aims The objective of this study is to determine the allocation pattern of caloric values in dominant species of the secondary forests that developed from deforestation of tropical rain forests in Xishuangbanna , Southwest China.

Methods We studied three $20 \mathrm{~m} \times 20 \mathrm{~m}$ plots in each of four communities: Trema orientalis forest, Mallotus paniculatus forest, Macaranga denticulata forest and Millettia leptobotrya forest, which were 2,4,6 and $>15$ years old. We recorded the species name and $D B H$ of all trees with a diameter $>3 \mathrm{~cm}$. Caloric values of 17 dominant tree species were determined using five sample trees of each dominant species : one small tree , three intermediate and one large tree. The sampled parts were leaves, branches, stems and roots. The caloric values of three replications for each sample part were measured with a SDACM-IIIa oxygen bomb calorimeter , with an error less than $100 \mathrm{~J} \mathrm{~g}^{-1}$. Differences were tested by $t$-tests.
\end{abstract}

Important findings The mean caloric values of $T$. orientalis , Mallotus paniculatus, Macarange denticulata and Millettia leptobotrya forests were $19182.11,19474.81,19551.38$ and $19445.95 \mathrm{~J} \mathrm{~g}^{-1}$, respectively. Generally speaking, the caloric values of the climax tree species were greater than those of the pioneer. Differences between leaves were significant, but differences between branches, stems, roots and the average were not significant. The caloric values of different parts were ranked as: leaves $>$ stems or branches $>$ roots at the average level, although $T$. orientalis, Vitex quinata and Aporusa yunnanensis showed lower caloric value in leaves. Results suggest that there was an increase in the utilization efficiency of energy with aging of forests . Ecosystems develop by systematically increasing their ability to convert incoming solar energy ; therefore , the transformation efficiency of energy was higher in climax trees than the pioneers. We postulated that in the early succession , ecosystems increase the absorption of energy though biomass accumulation ; therefore , pioneer trees show lower caloric values. Along with build-up of organic structure, however, ecosystems augment the fixation of the energy quality, and then caloric values can be enhanced per unit weight.

Key words energy , caloric value, dominant species , secondary succession , Xishuangbanna 
群落演替一直是生态学研究领域的热点问题， 尤其是在由于人类活动导致的植被变化业已影响到 人类生存环境的今天, 演替的研究更是众所瞩目的 焦点。遗憾的是, 以往有关群落演替的各种理论和 假说，在很大程度上都是基于对现象的描述和归纳， 并没有揭示群落演替的本质 (党承林等, 2002)。

能量是生命活动的基础。从很多方面来讲, 能 量是可以用来联接分子、细胞、器官、组织、个体、种 群、群落、生态系统甚至是景观等各个不同尺度的基 本单元 (Griffin, 1994)。能量是维持生态系统一切 功能过程的原动力, 因此我们可以将生态系统的进 程和格局按能量当量加以叙述和研究。自从 Long (1934) 第一个提出将热量计 (Oxygen bomb calorimeter) 方法应用于生态学, 并且较为系统地进行了植物 热值的研究之后, 氧弹式热力计成为研究生态系统 组成部分热值的重要方法。热值是指燃烧单位重量 干物质所释放出来的热量, 它反映了绿色植物在光 合作用中转化太阳能的能力, 是能量学分析的基础, 比单独的干重能体现能量的固定和储存过程中的更 多信息(Pitelka，1978)。

对于不同演替阶段的植被类型来说，它们能够 形成特定的耗散结构类型，体现出不同阶段的能量 结构特征。我们认为在森林演替的不同阶段, 随着 优势植物种类的相互替代, 群落的能量分配格局也 随之发生相应的变化。在每一个阶段, 必然有一个 与现阶段活动相适应的能量格局。因此本研究的目 的就是探讨云南西双版纳地区不同林龄次生群落类 型优势树种的热值分配格局。

\section{1 材料和方法}

\section{1 研究地点}

西双版纳位于我国西南部 $\left(21^{\circ} 09^{\prime} \sim 22^{\circ} 33^{\prime} \mathrm{N}\right.$, $\left.99^{\circ} 58^{\prime} \sim 101^{\circ} 50^{\prime} \mathrm{E}\right)$, 属西南热带季风气候，一年可分 为雨季、雾凉季和干热季, $5 \sim 10$ 月为雨季, 气候湿 热, $85 \%$ 的雨水集中在此期间降落; $11 \sim 12$ 月为雾凉 季, 降水量较少, 但早晚浓雾弥漫, 空气湿度较大; $3 \sim 4$ 月为干热季, 气温较高, 雨量少。年平均气温 $21.6{ }^{\circ} \mathrm{C}$, 最热月平均气温 $25.3{ }^{\circ} \mathrm{C}$, 最冷月平均气温 $15.5{ }^{\circ} \mathrm{C}$ 。年平均降雨 $1557.0 \mathrm{~mm}$, 年日照时数 $1828.0 \mathrm{~h}$, 有雾日数 $173.7 \mathrm{~d}$ 。坝区终年无霜。

因为其独特的地理位置和气候条件，该区分布 有热带季节雨林, 物种组成及丰富度见 Cao 等 (1996)。近半个世纪以来, 由于人口剧增、各种经济
活动的影响加剧，很多的原生植被已被不同类型的 次生植物群落所取代 (Zhang \& Cao, 1995)。本项研 究选择不同年龄的 4 种次生植被类型, 即山黄麻 (Trema orientalis) 群落、白背桐 (Mallotus paniculatus) 群落、中平树 ( Macaranga denticulata) 群落和思茅崖 豆(Millettia leptobotrya) 群落, 测定其优势种的热值， 以探讨群落演替过程中植物热值结构的变化。

山黄麻群落是西双版纳地区伴随刀耕火种出现 的常见植被, 弃耕后次生裸地被山黄麻幼苗侵占, 逐 渐形成山黄麻单优群落。该群落生长迅速、寿命短、 演替快(曹敏等, 1997; ;马志立等,1999)，当地人称山 黄麻为 短命树”。山黄麻通常为演替初期的优势 种, 随后被中平树或白背桐群落所替代(唐建维等， 1998 林露湘等,2002)。思茅崖豆群落是热带雨林 次生演替过程中继山乌柏 (Sapium discolor)、白背桐 先锋植物群落后形成的群落类型(唐建维等, 1997)。 本研究选择的思茅崖豆群落中, 有一块样地是中国 科学院西双版纳热带植物园生态站监测热带雨林被 破坏后设定的森林动态定位观测样地，根据历史记 载, 在此之前样地已经历了山乌柏、白背桐两个优势 种的替代过程, 目前思茅崖豆占优势。而且本次调 查在样地选择上特别注意对样地环境的控制，尽量 保持海拔、坡向等一致，演替过程中所受干扰均较 小, 以增加样地环境条件的一致性。

\section{2 样地选择和调查}

分别在各不同林龄的群落类型中各设立 3 块样 方, 面积为 $20 \mathrm{~m} \times 20 \mathrm{~m}$ 。对所有乔木进行每木调查, 记录样地内胸径 $>3 \mathrm{~cm}$ 的树木的种类、胸高直径 (离地表 $1.3 \mathrm{~m}$ 处)和树高等。

\section{3 取样}

根据重要值 $=$ 相对频度 + 相对显著度 + 相对密 度(Curtis \& McIntosh，1951)，计算每个树种在群落 中的重要值 然后将重要值之和达到 $50 \%$ 的前几个 树种定为优势种 (表 1)。并根据优势树种计算结 果, 在 2004 年 12 月进行采样, 每种类型样地中选取 其优势树种各 5 株, 按叶、枝、干、根 4 部分分别取 样。

树叶:分新、老叶采集,并将树冠从上到下分 3 层 按比例取样后混匀;

树枝 :分老枝、新枝采集，并考虑东、西、南、北、 中 5 个方位, 将树枝根据长短和基部粗细分为 3 组, 按比例取样 ;

树干 :在距地面 $1.3 \mathrm{~m}$ 处用生长雉取样;

树根 :按粗细分为两组。细根直径 $\leqslant 0.3 \mathrm{~cm}$; 粗 
根直径 $\geqslant 0.3 \mathrm{~cm}$ 。采样时考虑粗细比例。

顶极树种取样方法: 在 $1 \mathrm{hm}^{2}$ 的样地内设置 9 个 $20 \mathrm{~m} \times 20 \mathrm{~m}$ 的小样方。调查各样方内每个亚层 (按胸径分 $2 \sim 15 、 15 \sim 30 、 30 \sim 150 \mathrm{~cm}$ ) 的乔木数量, 记录每株树木胸径、高度、种名。每个小样方按 3 个 亚层中株数的一定比例分器官取样。

收集的样品按种分器官称鲜重后在 $80{ }^{\circ} \mathrm{C}$ 烘箱
中烘干至恒重，再粉碎过篮，压片燃烧。

\section{4 热值测定}

测定前将样品在 $105{ }^{\circ} \mathrm{C}$ 温度下烘 $3 \sim 4 \mathrm{~h}$, 然后 于干燥器中冷却。采用长沙三德仪器设备有限公司 生产的 SDACM- III a 型量热仪, 每个样品测量 3 次， 平行误差不超过 $100 \mathrm{~J} \mathrm{~g}^{-1}$ 取 3 次测定结果的平均 值。

表 14 种森林群落描述

Table 1 Description of the four forests

\begin{tabular}{|c|c|c|c|c|c|c|c|c|c|c|c|}
\hline $\begin{array}{l}\text { 森林类型 } \\
\text { Forest } \\
\text { type }\end{array}$ & $\begin{array}{c}\text { 林龄 } \\
\text { Age }\end{array}$ & $\begin{array}{l}\text { 地点 } \\
\text { Place }\end{array}$ & $\begin{array}{l}\text { 面积 } \\
\text { Area } \\
\left(\mathrm{m}^{2}\right)\end{array}$ & $\begin{array}{l}\text { 海拔 } \\
\text { Altitude } \\
(\mathrm{m})\end{array}$ & $\begin{array}{l}\text { 总物种数 } \\
\text { Total } \\
\text { number of } \\
\text { species }\end{array}$ & $\begin{array}{c}\text { 优势树种 } \\
\text { Dominant tree } \\
\text { species }\end{array}$ & $\begin{array}{c}\text { 树木个体数 } \\
\text { Total number } \\
\text { of trees }\end{array}$ & $\begin{array}{c}\text { 相对 } \\
\text { 优势度 } \\
R D O\end{array}$ & $\begin{array}{l}\text { 相对 相对 } \\
\text { 密度 频度 } \\
R D E \quad R F\end{array}$ & $\begin{array}{l}\text { 重要 } \\
\text { 值 } \\
I V\end{array}$ & $\begin{array}{l}\text { 优势物种重要值 } \\
\text { 占总物种的 } \\
\text { 百分比 }{ }^{1)}(\%)\end{array}$ \\
\hline $\begin{array}{l}\text { 山黄麻群落 } \\
\text { Trema orientalis } \\
\text { community }\end{array}$ & 2 & $\begin{array}{l}\text { 易武 Yiwu } \\
\left(22^{\circ} 00^{\prime} \mathrm{N},\right. \\
\left.101^{\circ} 23^{\prime} \mathrm{E}\right)\end{array}$ & $20 \times 20$ & 800 & 23 & $\begin{array}{c}\text { 山黄麻 } T \text {. orientalis } \\
\text { 微毛布荆 Vitex quinata }\end{array}$ & $\begin{array}{c}135 \\
16\end{array}$ & $\begin{array}{l}0.68 \\
0.03\end{array}$ & $\begin{array}{ll}0.58 & 0.08 \\
0.07 & 0.08\end{array}$ & $\begin{array}{l}1.34 \\
0.18\end{array}$ & 0.51 \\
\hline $\begin{array}{l}\text { 白背桐群落 } \\
\text { Mallotus } \\
\text { paniculatus } \\
\text { community }\end{array}$ & 4 & $\begin{array}{l}\text { 易武 Yiwu } \\
\left(21^{\circ} 57^{\prime} \mathrm{N},\right. \\
\left.101^{\circ} 28^{\prime} \mathrm{E}\right)\end{array}$ & $20 \times 20$ & 1250 & 37 & $\begin{array}{c}\text { 白背桐 Mallotus paniculatus } \\
\text { 中平树 Macaranga denticulata } \\
\text { 山乌柏 Sapium discolor } \\
\text { 湄公锥 Castanopsis mekongensis }\end{array}$ & $\begin{array}{l}159 \\
66 \\
52 \\
38\end{array}$ & $\begin{array}{l}0.39 \\
0.22 \\
0.10 \\
0.05\end{array}$ & $\begin{array}{ll}0.33 & 0.05 \\
0.13 & 0.02 \\
0.11 & 0.05 \\
0.08 & 0.05\end{array}$ & $\begin{array}{l}0.77 \\
0.37 \\
0.26 \\
0.18\end{array}$ & 0.53 \\
\hline $\begin{array}{l}\text { 中平树群落 } \\
\text { Macaranga } \\
\text { denticulata } \\
\text { community }\end{array}$ & 6 & $\begin{array}{l}\text { 预远 Mengyuan } \\
\left(21^{\circ} 41^{\prime} \text { N }\right. \\
101^{\circ} 25^{\prime} \text { E) }\end{array}$ & $20 \times 20$ & 900 & 45 & $\begin{array}{c}\text { 中平树 Macaranga denticulata } \\
\text { 湄公雉 Castanopsis mekongensis } \\
\text { 印度雉 Castanopsis indica } \\
\text { 细毛樟 Cinnamomum tenuipilis } \\
\text { 预海柯 Lithocarpus fohaiensis } \\
\text { 截果柯 Lithocarpus truncatus }\end{array}$ & $\begin{array}{l}110 \\
46 \\
32 \\
25 \\
31 \\
14\end{array}$ & $\begin{array}{l}0.42 \\
0.08 \\
0.07 \\
0.07 \\
0.03 \\
0.06\end{array}$ & $\begin{array}{ll}0.26 & 0.04 \\
0.11 & 0.04 \\
0.08 & 0.04 \\
0.06 & 0.04 \\
0.07 & 0.04 \\
0.03 & 0.03\end{array}$ & $\begin{array}{l}0.72 \\
0.23 \\
0.19 \\
0.17 \\
0.14 \\
0.12\end{array}$ & 0.53 \\
\hline $\begin{array}{l}\text { 思茅崖豆群落 } \\
\text { Millettia } \\
\text { leptobotrya } \\
\text { community }\end{array}$ & $>15$ & $\begin{array}{l}\text { 小磨公路 } \\
55 \text { 公里处 } \\
55 \mathrm{~km} \text { from } \\
\text { Xiaomo Gonglu } \\
\left(21^{\circ} 58^{\prime} \mathrm{N},\right. \\
\left.101^{\circ} 12^{\prime} \mathrm{E}\right)\end{array}$ & $20 \times 20$ & 800 & 56 & $\begin{array}{c}\text { 思茅崖豆 Millettia leptobotrya } \\
\text { 短序浦桃 Syzygium brachythyrsum } \\
\text { 浆果乌柏 Sapium baccatum } \\
\text { 披针叶楠 Phoebe lanceolata } \\
\text { 云南银柴 Aporusa yunnanensis } \\
\text { 西南猫尾木 Dolichandrone stipulata } \\
\text { 印度雉 Castanopsis indica } \\
\text { 玉荒 Barringtonia macrostachya }\end{array}$ & $\begin{array}{c}149 \\
30 \\
2 \\
24 \\
13 \\
8 \\
5 \\
4\end{array}$ & $\begin{array}{l}0.21 \\
0.08 \\
0.14 \\
0.03 \\
0.02 \\
0.03 \\
0.06 \\
0.03\end{array}$ & $\begin{array}{ll}0.46 & 0.04 \\
0.09 & 0.02 \\
0.01 & 0.01 \\
0.07 & 0.05 \\
0.04 & 0.04 \\
0.02 & 0.04 \\
0.02 & 0.01 \\
0.01 & 0.03\end{array}$ & $\begin{array}{l}0.71 \\
0.19 \\
0.16 \\
0.15 \\
0.10 \\
0.09 \\
0.09 \\
0.07\end{array}$ & 0.52 \\
\hline
\end{tabular}

$R D O:$ Relative dorminance $\quad R D E$ : Relative density $\quad R F:$ Relative frequency $\quad I V:$ Importnat value 1$)$ Percentage of $I V$ of dominant species in all species

\section{2 研究结果}

\section{1 不同林龄群落优势树种的热值差异}

为定量化评估各优势树种对总热值的贡献，我 们提出了优势树种贡献率的概念，即：优势树种贡献 率 $=$ 树种相对优势度/所有优势树种相对优势度之 和。由此，我们采用优势树种贡献率计算出每个群 落中所有优势树种的加权平均数，山黄麻群落、白背 桐群落、中平树群落及思茅崖豆群落优势树种的平 均热值分别为 $19182.11 、 19474.81 、 19551.38$ 和 $19445.95 \mathrm{~J} \mathrm{~g}^{-1}$, 各器官情况见图 1。各群落中最优 势种的热值变化与优势树种平均热值变化相吻合， 都是前期上升,后期略有下降(图 2)。

2.2 热值的器官差异
所有物种叶、枝、干、根的平均值分别为 $(20133.34 \pm 97.99) 、\left(\begin{array}{lll}19 & 371.96 \pm 56.13\end{array}\right)$ 、

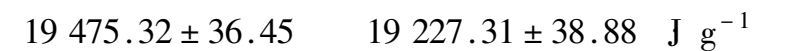
3 ) , 存在着叶 $>$ 干 枝 $>$ 根的规律, 且除枝和干 $(t$ test,$p=0.12)$ 、千和根 $(t$-test,$p=0.035)$ 差异末达到 极显著水平外, 其它均达到极显著 $(t$-test, $p<$ 0.001 )。尽管其它研究也得出了相似的结果 (Gower et al. , 1984 ;任海等,1999) ,但是具体到某一个物 种, 热值的器官排序不尽相同，我们根据各器官的热 值排列顺序将 17 个物种分为 3 类 (表 2)。

第一类是表 2 中第一栏,遵循叶 >干或枝 > 根 的一般规律, 第二类是第二栏, 虽然没有严格遵循第 一栏中的规律, 但还是遵循叶 > 根的规律; 第三类， 非常特殊, 山黄麻、微毛布荆( Vitex quinata) 和云南 
银柴 (Aporusa yunnanensis) 根的热值高于其叶的。

\section{3 先锋树种和顶极树种的热值比较}

选取热带季节雨林中具有较强顶极性质的树种 (蚁花 (Mezzettiopsis creaghii)、细罗伞 (Ardisia tener$a) 、$ 网脉核实 (Barringtonia mavrostachya)、白颜树 (Gironniera subaequalis)、番龙眼 (Pometia tomentosa) 和玉荵 (Barringtonia macrostachya) )及本次试验所测 定的典型先锋树种 (山黄麻、白背桐、中平树及思茅 崖豆)的热值进行比较。

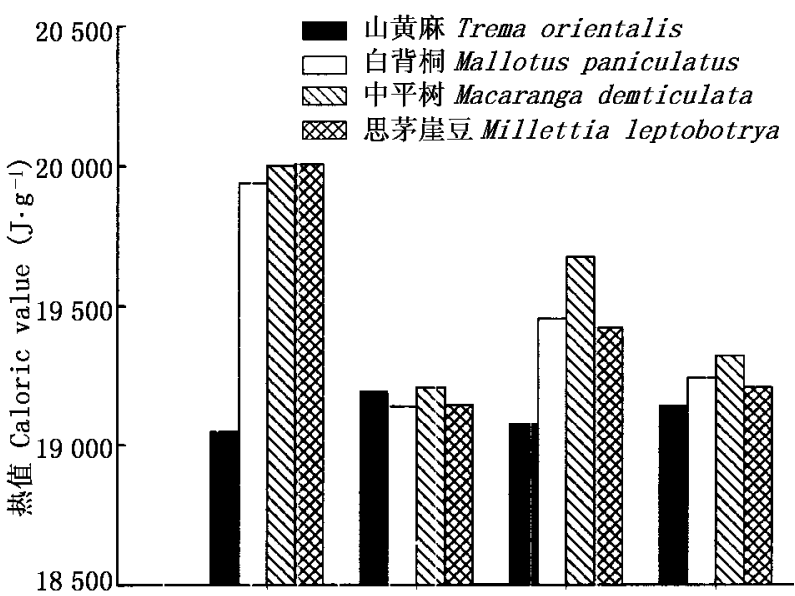

叶 Foliage 枝 Branch 干 Stem 根 Root

器官 Organ

图 1 西双版纳不同林龄先锋群落优势树种热值比较

Fig. 1 Caloric value analysis of dominant species in pioneer forests at different ages

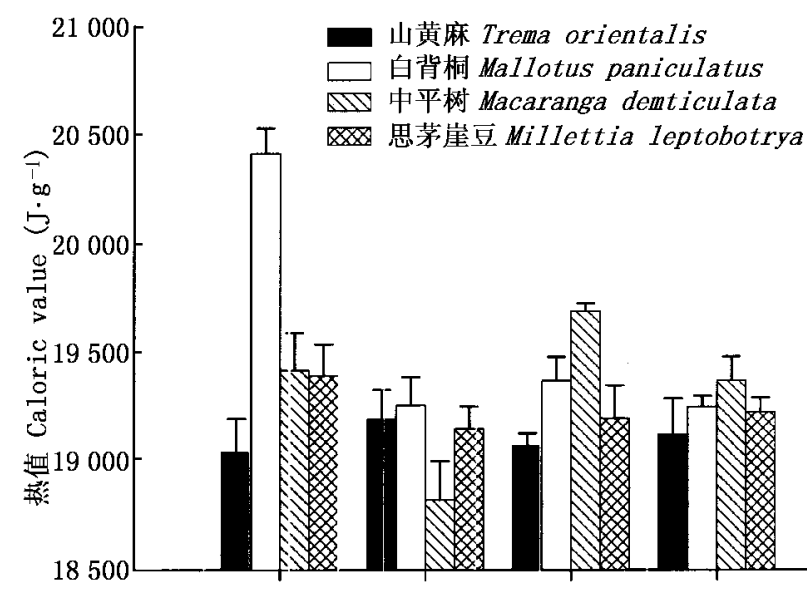

叶 Foliage 枝 Branch 干 Stem 根 Root 器官 Organ

图 2 西双版纳不同林龄群落优势种热值比较

Fig. 2 Caloric value analysis of the most dominant species at different ages

结果表明，无论是各个器官的单独比较还是整体 比较 顶极树种的热值均明显大于先锋树种，尽管除 叶片外 $(t$-test,$p=0.019)$ 其它末达到显著(图 4)。

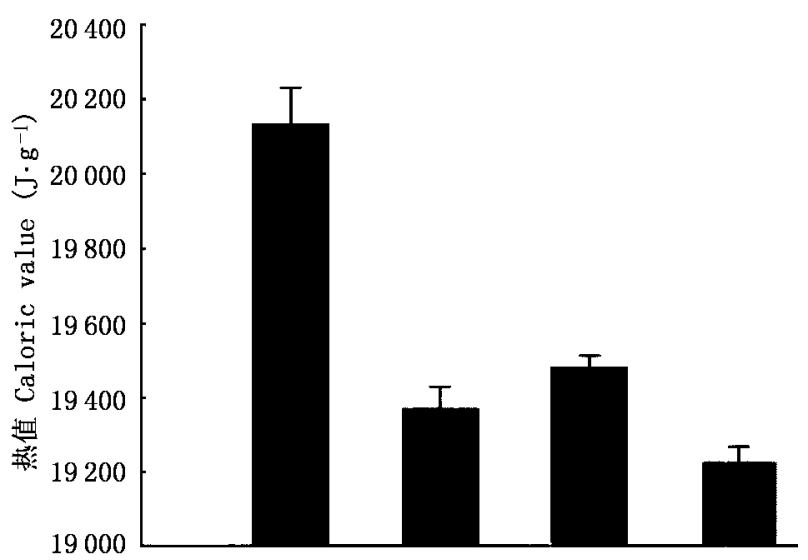

叶 Foliage 枝 Branch 干 Stem 根 Root 器官 Organ

图 3 先锋树种分器官热值比较

Fig.3 Caloric value analysis among organs of pioneer trees

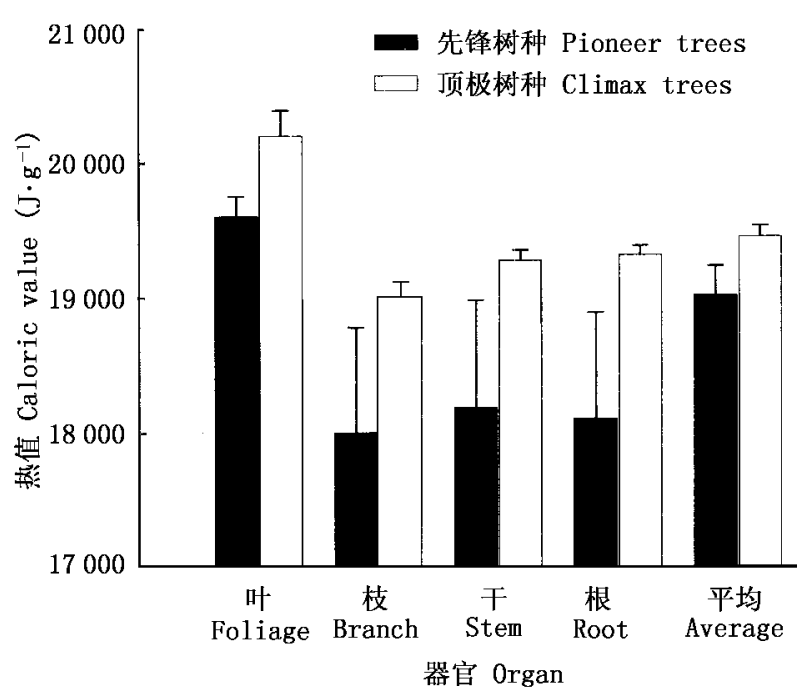

图 4 西双版纳先锋树种与顶极树种热值比较

Fig.4 Caloric value analysis of dominant species in pioneer forests at different ages

\section{3 讨 论}

\section{1 植物群落演替过程中的能量动态}

总之，随着年龄的增长，优势树种热值存在增长 的趋势。增长的原因应该是群落光能利用效率的增 加。根据 Kay 和 Schneider (1992) 及 Schneider 和 Kay (1994)的研究, 自然生态系统通过捕获与利用有用 能来耗散入射辐射。随着生长演化, 群落需要发展 具有更多能量流动渠道的更复杂的结构 增加物质 循环能力, 发展更复杂的生物多样性, 产生更多的等 级结构来增加能量的耗散。简言之, 生态系统向着 
表 2 所有树种热值器官排序

Table 2 Sequences of caloric values among the four organs

白背桐 Mallotus paniculatus

山乌柏 Sapium discolor

印度雉 Castanopsis indica

西南猫尾木 Dolichandrone stipulata

湄公雉 Castanopsis mekongensis

预海柯 Lithocarpus fohaiensis

截果柯 Lithocarpus truncatus

短序蒲桃 Syzygium brachythyrsum

披针叶楠 Phoebe lanceolata

思茅崖豆 Millettia leptobotrya

细毛樟 Cinnamomum tenuipilis

浆果乌柏 Sapium baccatum

玉蕊 Barringtonia macrostachya

中平树 Macaranga denticulata

山黄麻 Trema orientalis

微毛布荆Vitex quinata

云南银柴 Aporusa yunnanensis

枝

Branch
2
2
2
2
3
3
3
3
3
4
4
4
4
4
1
3
3

干 St

根 Root

叶 Foliage

$\begin{array}{lc}\text { Stem } & \text { 根 Root } \\ 3 & 4 \\ 3 & 4 \\ 3 & 4 \\ 3 & 4 \\ 2 & 4 \\ 2 & 4 \\ 2 & 4 \\ 2 & 4 \\ 2 & 4 \\ 3 & 2 \\ 3 & 2 \\ 2 & 3 \\ 2 & 3 \\ 1 & 3 \\ 3 & 2 \\ 4 & 1 \\ 1 & 2\end{array}$

$1 、 2 、 3 、 4$ :代表本器官在 4 个器官中热值的排列位置 Means the location of this organ's caloric value among the four organs
系统增加其耗散入射太阳能的方向发展。因此我们 可以期待, 越成熟的生态系统耗散所得到的能量的 能力越强 (Schneider \& Kay, 1994)。而热值随着群落 年龄的增加而增加, 恰是能量耗散能力增强的重要 基础。

与其它次生群落的热值相比, 思茅崖豆群落的 热值稍有降低, 是因为这个样地处于阴坡, 不能接受 到像其它 3 个群落那样在阳坡的充足光照。Long （1934）测定了 12 种栽培作物在不同光梯度下的热 值, 结果表明, 植物的热值储量与其生境中的光照强 度呈正相关, 接受的太阳辐射越弱, 热值降低越多。 从森林林冠到地表层, 光照强度的递减导致了植物 热值在垂直层面上的递减，所以森林中的热值格局 一般遵从森林上层到下层逐级递减的规律 (Golley, 1969 林鹏等, 1996; 任海等, 1999)。不同含能物质 的热值差异很大 : 油脂 $39.54 \mathrm{~kJ} \mathrm{~g}^{-1}$, 蛋白质 23.94 $\mathrm{kJ} \mathrm{g}^{-1}$ 碳水化合物 $17.15 \mathrm{~kJ} \mathrm{~g}^{-1}$, 纤维素 $16.8 \mathrm{~kJ}$ $\mathrm{g}^{-1}$ 淀粉 $15.96 \mathrm{~kJ} \mathrm{~g}^{-1}$ (祖元刚, 1990 ; Long , 1934 ; Ovington \& Heitkamp，1960），因此热值高的植物应该 含有更多的脂类物质和蛋白质。Meletiou-Christou 等 （1994）也曾提出光照充足处比阴暗处叶片的蛋白质 含量更高，这些都说明光强对植物的含能物质合成 有重要的影响, 随着光强的增加, 含能物质有增加的 趋势。

\section{2 热值在不同器官中的分布}

各器官循着叶、枝或干、根的顺序递减的规律与 前人研究相似 (任海等, 1999)。在任何特定的物种
中 器官之间的差异与器官的功能息息相关, 只有储 藏高能物质的器官才可能拥有高热值 (Pitelka, 1978) , 只有直接支持繁殖与生长的器官才会拥有高 热值。Golley (1969) 指出, 叶片拥有明显的高于其 它器官的热值, 主要原因是叶片是进行光合作用的 器官, 应该含有较高的蛋白质及脂肪, 另一方面, 是 因为它也可以合成一些高能物质。较高的热值一般 都预示着高能物质 (如脂类、淀粉等) 的大量存在 (Ovington \& Heitkamp , 1960 ; 祖元刚, 1990)。根、干 及枝是支持器官, 含有大量的纤维素, 因为纤维素的 热值低于蛋白质与脂肪, 所以, 这些器官的热值低于 叶片的热值。在这 3 种器官中，枝和干肩负着输送 及存储水与营养物质的任务, 而根则是距离叶片最 远的器官, 且其任务是吸收矿质元素及水分, 所以它 的热值最低(祖元刚, 1990)。

然而，对于山黄麻、微毛布荆及云南银柴来说， 这个规律似乎不再适用。从对所有物种的比较来 看, 它们根的热值差异相对于叶片的差异是极小的 $(F$-test , $p<0.001)$, 也就是说这些物种出现了根的 热值大于叶片热值的情况, 只能说明, 这些物种叶片 的热值变小了。山黄麻与微毛布荆都是处在强的光 照环境下, 为什么叶片的热值会如此低呢? Pitelka (1977) 发现 :一年生与多年生的羽扇豆在能量投资 方式上存在差异, 生长速率快、光合同化率高的一年 生羽扇豆将它 $61 \%$ 的能量投资在繁殖上, 直接投资 给种子的能量就占 $29 \%$, 这样, 它在稳定环境下的 竞争中处于劣势, 仅能在受干扰的地段存在; 而多年 
生羽扇豆在第二年开始才进行繁殖生长，且仅投资 $18 \%$ 的能量 $5 \%$ 直接投资于种子，大部分能量投资 于营养生长，从而在竞争中处于优势。因此我们推 测，因为山黄麻与微毛布荆都是短命物种，而短命物 种会把自己大部分的能量投资到繁殖上，而不是个 体的生长上，所以，它们的叶片具有低热值。云南银 柴是小乔木, 是群落下层树种, 不能接受到充足的光 照, 而光照条件是决定植物热值大小的重要条件, 并 且云南银柴是西双版纳地区一种常见的先锋树种， 仅在受干扰的地段存在。综合以上两点, 云南银柴 叶片的低热值不难理解。旷远文等 (2005) 在对鼎湖 山植物热值的研究中也曾发现, 在乔木二层和灌木 层中云南银柴的热值最低, 且根的热值高于叶的。 林鹏等 (1996) 曾发现福建和溪亚热带雨林中枫香 (Liquidambar formosana) 的热值相对较低, 他的解释 是枫香是落叶树种, 光合特性与常绿树种相差较 大。

\section{3 两组生态学种组的能量耗散对策分析}

顶极树种各器官的热值均明显大于先锋树种, 且叶片之间的差异均达到显著水平。叶片是植物进 行光合作用的最活跃器官, 是物质能量合成的重要 场所和运输枢纽, 因此叶片的热值变化最有规律性 (孙国夫等, 1993)。先前的文献也曾指出, 叶片对季 节变化的响应最敏感, 各种环境因子对植物生长的 影响也最能从叶片的热值变化上反映出来 (Hughes，1971)，不同物种之间的热值差异也主要体现在 叶片上。对全部先锋树种的热值差异分器官进行方 差检验的结果表明, 叶片与其它器官相比, 差异均达 到了显著水平 $(F$-test,$p<0.001)$ 。Whitmore (1990) 在总结先锋树种和顶极树种的主要特征时, 叶片的 寿命是重要特征之一, 先锋树种叶片的寿命短, 而顶 极树种叶片的寿命长。根据上文讨论, 寿命短则不 必积累太多能量用于生存, 因此, 叶片的热值在两种 树组中差异显著。而本研究就是着眼于在演替过程 中伴随着物种替代而产生的热值差异, 所以两组树 种器官热值 (尤其是叶片热值) 的差异具有重要意 义。这一现象反映了顶极树种的能量转换与利用效 率高于先锋树种。换言之, 顶极树种可以更好地利 用能量来构建自己的结构。凡是在生态系统中被保 留下来的物种都是可以很好地将能量转化为自身的 生长及繁殖、增加系统总的能量耗散的物种 (Toussaint \& Schneider, 1998)。通过这些比较我们可以知 道 顶极树种是在这场能量耗散的竞争中取胜的物 种。
我们据此推测，在群落演替初期，在没有很多生 物量支持的情况下, 生态系统增加能量耗散的主要 方式是通过生物量总量的增加来完成的，所以先锋 树种的热值相对来说较低。而当结构建成, 生物量 增加到一定程度, 已经没有足够的总量增长空间时， 生态系统将会改变能量储存方式, 主要通过单位质 量固定能量的增加,也就是热值的增加, 来耗散能 量。

\section{4 结 论}

本研究的主要结论可以归纳为 4 点: 1 ) 生态系 统向着系统增加其耗散入射太阳能的方向发展, 越 成熟的生态系统耗散它所得到能量的能力越强。植 物热值随着群落年龄的增长而增加, 这是植物群落 增加耗散能力的重要生态学对策 2)各器官循着叶、 枝或干、根的顺序递减，这与各器官执行的功能具有 极大的相关性, 只有直接支持繁殖和生长的器官才 会拥有较高的热值 3)相对于先锋树种来讲，顶极树 种可以更好地将能量转化为自身的生长和繁殖投 入, 更好地增加系统的能量耗散 ; ) 群落在不同的演 替阶段有不同的增加能量耗散的策略, 演替初期主 要是通过生物量总量的增加, 而后期主要是通过热 值含量的增加来耗散能量。

\section{参 考 文 献}

Cao M (曹敏), Tang Y (唐勇), Zhang JH (张建侯), Sheng CY (盛才余) (1997). Storage and dominants in soil seed banks under the tropical forests of Xishuangbanna. Acta Botanica Yunnanica (云南植物研究) , 19, 177 - 183. (in Chinese with English abstract)

Cao M, Zhang JH, Feng ZL, Deng JW, Deng XB (1996). Tree species composition of a seasonal rain forest in Xishuangbanna, Southwest China. Tropical Ecology, 37, 183-192.

Curtis JT, McIntosh RP (1951). An upland forest continuum in the prairie-forest border region of Wisconsin. Ecology, 32, 476 496.

Dang CL (党承林), Wang CY (王崇云), Wang BR (王宝荣), Li YL (李彦玲), Huang QM (黄其明) (2002). Succession and stability in plant community. Chinese Journal of Ecology (生 态学杂志), 21 (2), 30 - 35. (in Chinese with English abstract)

Feng ZL (冯志立), Tang JW (唐建维), Zheng Z (郑征), Song QS (宋启示), Cao M (曹敏), Zhang JH (张建侯), Xie JW (解继武) (1999). Biomass dynamics of the pioneer Trema orientalis community in the early stage of secondary succession of tropical forest in Xishuangbanna. Chinese Journal of Ecology (生 态学杂志) , 18(5), 1-6. (in Chinese with English abstract) 
Griffin KL (1994) . Calorimetric estimates of construction cost and their use in ecological studies. Functional Ecology, 8, 551 562 .

Golley FB (1969). Caloric value of wet tropical forest vegetation. Ecology, 50, 517 - 519.

Gower ST, Frederick DJ, Clark A III (1984). Distribution of energy in different-aged southeastern bottomland forests. Forest Ecology and Management, 9, 127 - 146.

Hughes MK (1971). Seasonal calorific values from a deciduous woodland in England. Ecology, 52, 923 - 926.

Kay JJ, Schneider ED (1992) . Thermodynamics and measures of ecosystem integrity. In: Mckenzie DH, Hyatt DE, Mvdonald VJ eds. Proceedings of the International Symposium on Ecological Indicators. Vol.1. Elsevier, Florida, 159-182.

Kuang YW (旷远文), Wen DZ (温达志), Zhou GY (周国逸)， Liu SZ (刘世忠), Zhang DQ (张德强) (2005). Caloric values of dominant species in the different layers of lower subtropical monsoon evergreen broad-leaved forest at Dinghushan Mountain. Journal of Beïing Forestry University (北京林业大学学报), 27(2), 6-12. (in Chinese with English abstract)

Lin P (林鹏), Shao C (邵成), Zheng WJ (郑文教) (1996).

Study on the caloric values of dominating plants in a subtropical rain forest in Hexi of Fujian. Acta Phytoecologica Sinica (植物 生态学报), 20,303-309. (in Chinese with English abstract) Lin LX (林露湘), Cao M (曹敏), Tang Y (唐勇), Fu XH (付 先惠), Zhang JH (张建侯) (2002). Tree species diversity in abandoned swidden fields of Xishuangbanna, SW China. Acta Phytoecologica Sinica (植物生态学报), 26, 216-222. (in Chinese with English abstract)

Long FL (1934). Application of calorimetric records to ecological research. Plant Physiology, 9, 323-337.

MeletioutChristou MS, Rhizopoulou S, Diamantoglou S (1994). Seasonal changes of carbohydrates, lipids and nitrogen content in sun and shade leaves from four mediterranean evergreen sclerophylls. Environmental and Experimental Botany, 34, 129 - 140.

Ovington JD, Heitkamp D (1960). The accumulation of energy in forest plantations in Britain. Journal of Ecology, 48, 639-646.

Pitelka LF ( 1977 ). Energy allocation in annual and perennial lupines (Lupinus: Leguminosae). Ecology, 58, 1055 - 1065. Pitelka LF (1978). Variation in caloric values of annual and lupines (Lupinus: Leguminosae). American Midland Naturalist, 99, $454-462$.

Ren H (任海), Peng SL (彭少麟), Liu HX (刘鸿先), Cao HL (曹洪麟), Huang ZL (黄忠良) (1999). The caloric value of main plant species at Dinghushan, Guangdong, China. Acta Phytoecologica Sinica (植物生态学报), 23, 148 - 154.（in Chinese with English abstract)

Schneider ED, Kay JJ (1994) . Life as a manifestation of the second law of thermodynamics. Mathematical and Computer Modelling, $19,25-48$.

Sun GF (孙国夫), Zheng ZM (郑志明), Wang ZQ (王兆骞)

(1993) . Dynamics of caloric values of rices. Chinese Journal of Ecology (生态学杂志), 12(1), 1-4. (in Chinese with English abstract)

Tang JW (唐建维), Zhang JH (张建侯), Song QS (宋启示), Feng ZL (冯志立) (1997). Analysis on the characteristics of Millettia leptobotrya community in Xishuangbanna. Guihaia (广 西植物), 17, 338 - 344. (in Chinese with English abstract) Tang JW (唐建维), Zhang JH (张建侯), Song QS (宋启示), Cao M (曹敏), Feng ZL (冯志立) (1998). A preliminary study on the biomass of secondary tropical forest in Xishuangbanna. Acta Phytoecologica Sinica (植物生态学报), 22, 489 498. (in Chinese with English abstract)

Toussaint O, Schneider ED (1998). The thermodynamics and evolution of complexity in biological systems. Comparative Biochemistry and Physiology-Part A: Molecular \& Integrative Physiology, $120,3-9$.

Whitmore TC (1990). An Introduction to Tropical Rain Forests. Clarendon Press, Oxford.

Zhang JH, Cao M (1995). Tropical forest vegetation of Xishuangbanna, SW China and its secondary changes, with special reference to some problems in local nature conservation. Biological Conservation, 73, $229-238$.

Zu YG (祖元刚) (1990). An Introduction to Energetic Ecology (能量生态学引论). Jilin Science and Technology Publishing House, Changchun. (in Chinese) 